\title{
The Perceptions of Undergraduate Students on Intercultural Communication in Universiti Sains Islam Malaysia (USIM).
}

\author{
Selvarani P. Kovil Pillai ${ }^{\mathrm{a}} \&$ Dr Rosninawati Hussin ${ }^{\mathrm{b}}$ \\ aLecturer, Communication Programme, Faculty of Leadership \& Management, Universiti Sains Islam Malaysia, Nilai, \\ NegeriSembilan, Malaysia.012-5633650,rani@usim.edu.my. \\ bSenior Lecturer, Communication Programme, Faculty of Leadership \& Management, Universiti Sains Islam Malaysia, \\ Nilai, Negeri Sembilan, Malaysia
}

\begin{abstract}
With the increase of globalization and migration, the study of intercultural communication has become more and more vital. The Ministry of Higher Education Malaysia has made a move to transform the landscape of tertiary education by intensifying internationalization and ensuring 10\%-30\% enrolment of international students in local universities and promoting the country as the education hub in the region. Taking the case study of the international students who are undergraduate students in Universiti Sains Islam Malaysia (USIM), this study focused on the intercultural communication aspect, the cultural barriers as well as the adaptation of these student in the new environment. The data was drawn from in-depth interviews conducted on the basis of the responses on 10 undergraduate students: four from Afghanistan, three from Nigeria, one each from Singapore, Indonesia, and Bangladesh. The findings showed issues facing by these students are not only about food and weather, but language, academic and finance systems and also feeling of alienation and discrimination.
\end{abstract}

Keywords: perception, intercultural; communication; adjustment

\section{Introduction}

In recent years, Malaysia has witnessed an influx of foreign students coming to Malaysia to pursue their education. This is in line with the Malaysian Government's aspiration to turn Malaysia into a global education hub and to attract 200,000 international students by 2020 (Rahman, 2016). The influx of international students in universities has various benefits. From economic aspects, it not only profits the economy of students' countries of origin and the host countries' economy but also the international students and local students themselves (Pandian, 2008). There are some 120,000 international students $(151,000$ including school children) studying in Malaysia.
More than 30,000 are pursuing postgraduate degrees. International students currently contribute about RM7.9 billion to the nation's economy and this is expected to increase to about RM15.6 billion per annum by 2020 (Rahman, 2016). However, this presence of international students also triggers challenges as well as opportunities in addressing the issues of diversity in educational institutions. According to Banumathy \& Vikneswaran (2010), "as international students come to Malaysia, they experience cultural difference both in academic and social aspect". Though there are a number of studies done about international students in Malaysia, but very little information was revealed of their communicative experiences on 
campuses. Most of studies are carried out among international students from the public and private universities which consist of students who are multiracial and from various religion and beliefs. But this is a different scenario, whereby all the students in this case study were from Universiti Sains Islam Malaysia (USIM) are Muslims. Though the international students originated from various countries but they are similar in religion with the local students.

Therefore this study examined perceptions of intercultural communication and adjustment of the international students in
USIM. USIM which is situated in Nilai, Negeri Sembilan has been taking measures to increase the number of international students. Table 1 revealed the number of international student who are undergraduates. The highest number of international student enrollment in undergraduate programs is in 2012 and 2013. Then it dropped drastically from the total of 49 students to 9 students in year 2014 and 7 students respectively in 2015. Ultimately, the number of students increased to 16 students in 2016, about $128.6 \%$ increase from 2015.

Table 1. Number of International Undergraduate Students in USIM (2010 - 2016)

\begin{tabular}{llll}
\hline Year & Male & $\begin{array}{c}\text { Female } \\
\text { Total }\end{array}$ \\
\hline 2010 & 6 & 4 & 10 \\
2011 & 5 & 6 & 11 \\
2012 & 29 & 21 & 50 \\
2013 & 24 & 25 & 49 \\
2014 & 2 & 7 & 9 \\
2015 & 5 & 2 & 7 \\
2016 & 4 & 12 & 16 \\
& & & \\
\hline
\end{tabular}

The total number of international undergraduate students in USIM is 91 students and the highest originated from Afghanistan followed by Singapore and Nigeria. Refer to Table 2.

Table 2. Number of International Undergraduate Students According to Country of Origin.

\begin{tabular}{ll}
\hline Name of countries & $\begin{array}{l}\text { Number of } \\
\text { Students }\end{array}$ \\
\hline Afghanistan & 23 \\
Singapore & 18 \\
Nigeria & 13 \\
Indonesia & 11 \\
Thailand & 9 \\
Brunei & 7 \\
Gambia & 2 \\
Jordan & 2 \\
Arab & 1 \\
Cambodia & 1 \\
Bangladesh & 1 \\
China & 1 \\
Algeria & 1 \\
Sri Lanka & 1 \\
\hline
\end{tabular}


As for the enrollment based on faculty, the highest number is in the Faculty of Science and Technology, 31 students followed by Faculty of Quranic and Sunnah Studies, 21students and Faculty of Leadership and Management, 14 students. Refer to Table 3.

Table 3. International Undergraduate Students based on Faculties.

\begin{tabular}{ll}
\hline Faculty & $\begin{array}{l}\text { Number of } \\
\text { Students }\end{array}$ \\
\hline $\begin{array}{l}\text { Faculty Science and Technology } \\
\text { (FST) }\end{array}$ & 33 \\
$\begin{array}{l}\text { Faculty of Quranic and Sunnah } \\
\text { Studies (FPQS) }\end{array}$ & 21 \\
Faculty of Leadership and & 14 \\
Management & 9 \\
(FKP) & \\
Faculty Syariah dan Law (FSU) & \\
Faculty Economy dan Muamalat & 7 \\
(FEM) & 7 \\
Faculty of Major Languages Studies & \\
(FPBU) & \\
\hline
\end{tabular}

This research focused on the perceptions of international undergraduate students on intercultural communication. According to Berelson \& Steiner (1964), interactions are influenced by perception, "the process by which people select, organize, and interpret sensory stimulation into a meaningful and coherent picture of the world" (Berelson \& Steiner, 1964, p. 88). In-depth interviews were conducted with 10 undergraduate students: four from Afghanistan, three from Nigeria, one each from Singapore, Indonesia, and Bangladesh to analyze the perceptions of the international students about intercultural communication in USIM. This paper aims to explore the experiences of students and challenges they faced due to differences in culture and communication. The researcher also analyzed the social friendship networks of these students, their intercultural communication competence and the perceived and other communication problems and challenges encountered while studying in USIM.

The following paragraphs will discuss the issues, challenges and expectation from international students based on some empirical studies by other researchers. A study on international student experience conducted by Slethaug \& Manjula (2012) at a mid-sized Malaysian tertiary institution on 78 international students from 17 countries with majority from Middle East and Africa. Findings show that students were frustrated with the administrative process such as admission, subject registration and subject add-drop during their first semester of study. However, the frustration was less pertinent during their second semester when they were more familiar to the system. Another empirical study conducted by Nur Sofurah (2011) on international student learning experience at one of the Malaysian technical and vocational education university found that international students seems to disengage from other local students may be due to the lack of communication skills. Abdul Embong (2013) examined the perceived challenges face by lecturers, administrators and both international and local students at public and private 
institutions through interviews and focus group found that international students have undergone social stress due to the disengagement from the locals.

Hooley \& Horspool (2006) have conducted an empirical study on student and staff perception on non-native speakers at one of the British university. Amongst the challenges were perceived cultural gap, low participation in class, poor learning, poor understanding of academic convention for example plagiarism, linguistic difficulty and other personal problems making the teaching experience very time consuming. Therefore this research is also investigating international student perceptions on intercultural communication.

\subsection{Perception}

In this context, perception is defined as a belief or opinion held by international students on intercultural communication that is happening in the university. Perception is an important element in intercultural communication. Zimmermann (2009), in her research examined perceptions of intercultural communication competence and adaptation in international students studying on an American campus. She suggested that while the affective and behavioral dimensions of intercultural communication competence are related to students' satisfaction with their communication skills, talking with American students was the single most important factor in perceptions of communication competency and adjusting to American life (Zimmermann, 2009).

According to Hilgard, Atkinson \& Atkinson (1979), perception is defined as the process of becoming aware of objects, qualities, or relations by way of the sense organ. They explained that while sensory content which is the five senses is always present in perception, what is perceived is influenced by set and prior experience, so that perception is more than a passive registration of stimuli impinging on the sense organs. Student perception on intercultural communication is pertinent to the well-being of his/her status as a student in the university.

\subsection{The Transition Model}

The Transition Model is related with how people face the culture shock and they adapt to the new culture at the host country. Each person has a preferred way of dealing with new situations. Psychologists have found that most individual prefer either a "flight" or a "fight" approach to unfamiliar situations (Martin \& Nakayama, 2010, p. 324). Students who prefer the flight approach may choose to keep away from the stresses of intercultural interaction by speaking and reading in one's native language, socializing with friends of similar background. According to Martin \& Nakayama, "Taking time out or small periods of "flight" allow the students some needed rest from the challenges of cultural adaptation (2010). However, if the student remained in the "flight" mode for longer period of time, then it can affect the productivity and the performance of the student and they lose the opportunity for intercultural learning. The second method is the fight approach, where the individual choose to jump in and participate in the activities of the host country (Martin \& Nakayama, 2010). International students may try to learn the new language, taking the risk and making mistakes, take a lot of initiatives and often make cultural blunders. Again getting stuck in the "fight" mode can be unproductive because students who take this approach to the extreme tend to act on their surrounding with little flexibility and are likely to criticize the way things are done in the new culture (Martin \& Nakayama, 2010). Neither of these preferences for dealing with new situations is inherently right or wrong because individual preference is a result of 
family, social, and cultural influences. In the context of the university, the local students, staffs, and lecturers who are the host can also influence the communication of the international students. A third alternative is the "flex" approach, in which the student can use a combination of productive "fight" or "flight" behaviours. The idea is to "go with the flow" while keeping in mind the contextual elements. Hostile contexts (such as racism or prejudice) may encourage extreme responses, but a supportive environment (tolerance) may encourage more productive responses. The three approaches focused on the psychological feelings of the students, on how comfortable they feel.

\subsection{The Integrative Model}

The Integrative Model, which is a model of adaptation developed by communication scholar Young Yun Kim (2005) (as cited in Martin \& Nakayama, 2010, p. 324). Kim suggests that adaptation is a process of stress, adjustment, and growth. As individuals experience the stress of not fitting in with the environment, the natural response is to seek to adjust. Adaptation occurs through communication. That is, the international student communicates with individuals in the new environment and gradually develops new ways of thinking and behaving. In the process, the student achieves a new level of functioning and acquires an intercultural identity. However, some students have difficulty adapting to new ways. According to the cognitive dissonance theorist of the 1950s, individuals typically have three options when confronting ideas or behaviours that do not fit with previously held attitudes: they can (i) reject the new ideas, (ii) try to fit them into their existing frameworks or (iii) change their frameworks (Festinger, 1957).

\section{Methodology}

This research is about the perceptions of the international students on intercultural communication. These students are undergraduates who are studying in USIM. The data was drawn from in-depth interviews conducted on the basis of the responses on 10 undergraduate students: four from Afghanistan, three from Nigeria, one each from Singapore, Indonesia, and Bangladesh. The participants were comprised of eight male students and two female students. The length of time they stay in Malaysia is from two to four years. The interview took place in the library, faculty office and empty classroom during lunch break. The interview was semi-structured and questions were open, with the intention of leading to further discussion among the respondents. The questions were asked with a view to understand how students perceived intercultural communication individually. The data were analyze in order to find out the dimensions of difficulties the foreign students encounter, recurring response from each question were organized and coded. Based on the recurring response, the dimensions themes were identified.

\section{Results and Discussion}

The answers given by the participants were transcribed, with attention to what was said. The data was analyzed by looking particularly at the themes, this gives an insight into how the participants view themselves and their intercultural communication with others.

\subsection{Adjustment}

From the arrival of international students to the university, they will encounter many different and unexpected problems and as a result, students who live in a foreign country need to make adjustment. In terms of teaching 
and learning style, international students experience difficulties because of different method and style compared to their home country. Students may need to adjust to a new educational system, which differs considerable from the methods of study in their own country (Mehdizadeh \& Scott, 2005). This statement was supported by Furnham (2004), who found that American students who travelled to another country faced difficulties over academic issues, language, housing, economic issues, their inability to become socially accepted, health and recreation issues, and racial prejudice. There are many factors that students need adjustment such as academic style, environment, social-cultural factors, emotions, communication apprehension and also sense of belonging to their university.

In the context of USIM students, for example students from Nigeria said that they found that the way lectures are done in USIM is so different from Nigeria. In Malaysia, a lecturer will deliver his or her lecture for two hours, then, at the end, students are allowed to ask questions. Students from Nigeria find it rather bored listening to long lectures. Back in their country, students are encouraged to ask as many questions as possible while the lecture is going on. In fact, they can argue whatever the lecturer says, and thus, their experience back in Nigeria is so different compared to Malaysia. They also mentioned that the local students are so quiet in the class and do not want to involve in discussion during the lecture or tutorial.

The students also mentioned about missing their family members and friends. Another hardest thing for them is the weather condition. Many of these students felt that Malaysia is too hot compared to their country. According to Misra and Castillo (2004), all international students go through the process of adjusting to a new educational system and social environment. Adjustment to these new environments can be a stressful process ( $\mathrm{Li} \&$ Gasser, 2005) since they have to adapt to new cultural values, foods, weather, etc. The following barrier is food which is mentioned by almost all the students. Some of the student felt that food in Malaysia is not tasty compared to their food. Many of the students choose to cook their own food using the spices and ingredients from their countries.

Besides food and weather, international students also complained about the systems in the university which are not so friendly. There are students who are unhappy with the management especially the academic administration system. For example, some of the students have paid the fees, but were not issued the examination slip to sit for the final examination. They also complained about dissemination of information in Malay language. Language is always a barrier among the international students. Language seems to be the major problems that they faced in their learning (Banumathy \& Vikneswaran, 2008; Akida, 2008). As a result, they could not access to important information pertaining to their studies and activities in campus. Almost all the international students could not speak in Bahasa Malaysia, which is the official language of Malaysia. This makes it more difficult for them to communicate with people outside campus. For example, to communicate with the mechanic when the car broke down, not only they do not understand the Malay language and when they speak in English, people could not understand because of the accent and slang of the communicator.

However, Singaporeans and Indonesian students have no problem to blend well into Malaysian culture because of similarity in the language, culture, food and religion too. Perhaps adaptation is much easier for these students whose original ethnic characteristics coincide with the environment in Malaysia. Therefore they faced few barriers compared to other international students. 


\subsection{Discrimination}

Differences in physical appearances, language, verbal and nonverbal behaviours, rules and norms of social engagement, and economic and political ideology, as well as religious beliefs, ceremonies and rituals, are some of the major ethnicity gaps faces by the international students. Of particular importance is the degree of salience of noticeable "ethnic marker," including distinct speech patterns and physical characteristics (e.g., skin colour, facial features, and physique). Such markers often add to the overall "foreignness" of strangers, playing favourable or unfavourable role in the strangers' subsequent communication with host cultures. Lysgaard (1955) and Sewell and Davidsen (1961) describe Scandinavian students as having little difficulty in adapting to life in the United States, while Lambert and Bressler (1956) and Bennett, Passin \& McKnight (1958) report considerable difficulty on the part of students from India and Japan, respectively. This is also felt by some of the African students had bad experience with fellow students and staffs in campus and outside campus as well. For example, they had bad encounters with shopkeepers and police. They claimed that shopkeepers always charged them extra. They are always being cheated by the shopkeepers. In one the Nigerian student, the owner of a mobile telephone shop sold him a fake telephone that could not work properly. When he went back to confront the shopkeeper, he was so furious that he called the police and handed the student to the police. The police put him in the lock-up until his fellow student also from Nigeria had to bail him out.

At campus also these foreign students experience discrimination. They claimed that they are being alienated by local students who are quite hesitant to work with foreign students. As a result, they tend to form their own group when it comes to group-work. They choose the "flight" mode to keep away from the local students. For example, they prefer to form groups among the international students to do their group assignments. Language is also a barrier because many local students unable to communicate in English. The language used in lectures and tutorials are English or Arabic. Some of the lectures are in English and some are in Arabic language depending on the lecturer that teaches the particular course. Most of the local students especially in the first and second year are not proficient in either language. As for the Nigerians, they speak very fluently in English and have problem to speak the Arabic language. Therefore during the lectures or tutorials in English, the international students especially from Nigeria, or even Indonesia are able to participate and communicate with ease using the English language compared to local students. These local students are mostly from the Religious School background. As a result, the foreign students especially, from Nigeria tend to control the discussion in the classroom. Students from Afghanistan also mentioned that they are very frustrated with the local students who are not communicating because lack of proficiency in English and they are also feeling rather inferior and timid. Even when the foreign students try to mingle with the local students, they just keep away from the international students. Some of the male students from Afghanistan also mentioned about female local students who are not friendly towards the male students. Even when they try to communicate, the local students especially the female students tend to keep a distance from the international students. They claim that they have no problem communicating with different gender in their own country.

Another problem that was highlighted by the students was concerning their placement in the industry for internship. The major problem facing by the final year students are getting a place for internship. Though it is compulsory for students to undergo their internship or industrial training during their final 
semester but most of the time, their applications are often rejected by the government and also the private sector. According to the Coordinator of Centre for Innovation, Industrial \& Community Networking, USIM, Dr. Hanim Misbah, who is in charge of Internship and Industrial Training, many organizations are skeptical about taking foreign students to do their internship because of the stigma as a foreign student. Some organization especially the private sector had openly rejected the application of the international students because of some bad past experiences. However, some embassies are also cooperative to take their students to do internship at the embassy. Sometimes the embassy also produce letters stating that the students are "clean" in the sense they have no problem with their visa or passport and free from crime or illegal acts. Sometimes the international students get to do his/her internship at multinational companies (MNC) which based in his/her country. The last alternative would be to place the students at various departments at the university.

\subsection{Attitudes and Values}

According to some of the international students from Afghanistan, they said that their course mates are rude and also being racist. A participant shared their experience when a group of international students decided to invite a group of locals to come and share their food. They took so much trouble to prepare the meal. The local students came and really enjoyed the food. The next day, they saw them at campus but the local students did not even greet the international student who had put so much of effort to prepare the traditional meal for them. One Nigerian student also mentioned about difference in attitudes and values.
"In Nigeria, when someone do wrong in our country, we confront them but in Malaysia, when we confront them, they get very angry". "for an example the bus driver at the university was busy talking on his mobile phone for more than 15 minutes, and students were late to class, but when I confronted him, he was so angry with me.”

There have been various studies that stressed the cases that were faced by the international students who failed to adapt in their new country. For example, Sadhu and Asrabadi (1994) studied the case of 128 international students who were stressed because of perceived deprivation $\backslash$ alienation,

loneliness \homesickness, hate, fear, stress due to change, and guilt because of not being able to adapt to the new environment in the host country. Research by Neuliep and McCroskey (cited in McCroskey, 1977) found that sojourners who cannot communicate effectively in their new host country tend to be more passive and engage in communication with others less than the norms. Symptoms of communication apprehension were identified as feeling hopeless, frustrated, shameful, stupid, less assertive, having low self-esteem, and being overly sensitive to criticism. These traits can lead to depression if not treated (McCroskey, 1977). In the context of USIM students, some of the international student said that they will not recommend the university to their relatives or friends in their country. This shows that the international undergraduate students are not comfortable with the present situation in USIM. It is important to take care of 
the present students who are studying in the university now because they are the agents that can promote or demote the university among their circles of friends and community. If these students are not happy and have negative perceptions to the university then this can affect the goal and dreams of Malaysian universities to be the education hub for international students. This study is expected to give a real perspective to policy-makers either in the university or policy makers in the country of origin so that they can make a policy to suit the social and academic needs of international students at USIM.

\section{Conclusion}

The findings of this study can provide a platform to understand the barriers faced by the international undergraduate students in terms of intercultural communication in USIM. Even though the undergraduate students in USIM are all from same religion background but they are still facing a lot of challenges due to differences in culture and communication. The findings also suggest a direction for future research in this area. For example, the perceptions of the local students about the foreigners and to figure the relationship between the two dimension of language and cultural awareness. The university has to take further steps to improve the intercultural communication of students, especially international students, so that they will feel comfortable to study in a new environment. The local students also need to be trained to be an effective intercultural communicator, and to respect and be friendly to international students. The university also has to take various measures to enhance its academic and finance system, and all other services specialized to cater the needs of the international students. This is to ensure that the international students, especially the undergraduate students will be able to communicate effectively in terms of intercultural communication with the lecturers, administrators and students both local and international. The university should train the frontline especially the administrators and staff that handling these students at the faculty, Academic Administrative department and so on. Though some students are required to take a course, Intercultural Communication but it is not sufficient. Students must be exposed to various programs that can enhance their understanding on intercultural communication as well as cross-cultural communication. 


\section{Reference}

Akida Hiroko. (2008). The Challenging Face of Transnational Education in Malaysia : A Case Study of International Offshore University Programs. Thesis Ph.D. of Faculty of Graduate School, University of Minnesota.

Banumathy, D. \& Vikneswaran, N. 2010. In Sarjit, K., Morshidi Sirat \& Azman Norzaini. 2010. (ed.). Globalisation and Internationalisation of Higher Education in Malaysia. Pulau Pinang : Penerbit USM.

Bennett, J., Passin, J., \& McKnight, R. (1958). In search of identity: Japanese overseas scholars in the United States. Minneapolis: University of Minnesota Press.

Berelson B. and Steiner G.A. (1964). Human Behaviour: An Introductory of Scientific Findings.New York: McGraw Hill.

Embong, A. B. 2013. In Tham Siew Yean (ed.). 2013. Internationalizing Higher Education in Malaysia : Understanding, Practices and Challenges. Singapore: ISEAS.

Festinger, L. (1957). A Theory of Cognitive Dissonance. Stanford, CA: Stanford University Press.

Furnham, Andrian. (2004). Foreign students: Education and culture shock. The Psychologist. 17 (1), 10- 19.

Gudykunst \& Kim. (2003). Communicating with strangers. New York: McGraw Hill.

Hilgard E. R., Atkinson R., \& Atkinson R.C. (1979). Introduction to Psychology, 7th ed. New York: Harcourt Brace Jovanovich.
Hooley, T. \& Horspool, P. (2006). Two sides of the same story? Staff and student perceptions of the non-native speakers experience of the British academic system. The East Asian Learner 2(2) Pg. $1-10$.

Lambert, R., \& Bressler, M. (1956). Indian student on an American campus. Minneapolis: University of Minnesota Press.

Li. A. \& Gasser, M. B. (2005). Predicting Asian international students' sociocultural adjustment: A test of two mediation models International Journal of Intercultural Relations. Volume 29, Issue 5, September 2005, Pages 561-576

Lysgaard, S. (1955). Adjustment in a foreign society: Norwegian Fullbright grantees visiting the United States. International Social Science Bulletin, 7, 45-51.

Martin, J. N. \& Nakayama, T. K. (2010). Intercultural Communication in Contexts. New York: McGraw Hill. 322-324.

McCroskey, James. (1977). Oral communication apprehension: A summary of recent theory and research. Human Communication Research, 4, 78-96.

Mehdizadeh, N., \& Scott, G. (2005). Adjustment problems of Iranian international students in Scotland. International Education Journal, 6(4), 484-93

Misra, Ranjita \& Castillo, Linda G. (2004) Academic stress among college students: Comparison of American and international students. International Journal of Stress Management, 11(2), 132148. 
Nur Sofurah, M.F. 2011. From Theory to Practice : The Learning Challenges for International Students to Succeed in a Malaysian Technical and Vocational (TVE) Higher Education Institution. Proceeding The Third Asian conference on Education 2011, pg. 496-505.

Pandian, Ambigapathy. (2008). Multiculturalism in higher education: A case study of Middle Eastern students' perception and experiences in a Malaysian university. The International Journal of Asia Pacific Studies, 4 (1), 33-57.

Prentice-Hall, Inc.

Rahman, D. (2016,June 23). Malaysia's higher education mid-year report. The Star.
Sadhu, Daya \& Asrabadi, Badiolah. (1994). Development of an acculturative stress scale for international students: Preliminary findings Psychological Reports, 75, 435-448.

Sewell, W.H., \& Davidsen, O. H. (1961). Scandinavian students on American campus. Minneapolis: University of Minnesota Press.

Slethaug, G. \& Manjula, J. (2012). The Business of Education : Improving International Student Learning Experiences in Malaysia. World Journal of Social Sciences. 2(6):179-199.

Zimmermann, Stephanie. (2009). Perceptions of intercultural communication competence and international student adaptation to an American campus. Journal Communication Education. Volume 44, 1995 - Issue 4 32-335 
Volume 1, Number 1, April 2017; (93-104) 